\title{
A Study of Quality of Life of Patients on Regular Haemodialysis at Sohag University Hospital 2015
}

\author{
Ahmed Fathy Hamed*, Rasha Abd El-Hameed Ali*, Emad Ahmed Mohamed \\ youssef** and Lamiaa Ahmed Abd El-Rahim*. \\ *Public health and community medicine department. ** Internal medicine \\ department, Sohag University
}

Received: December 2016 Accepted: February 2016

\begin{abstract}
Background: Haemodialysis has a considerable impact on health related quality of life. Haemodialysis alters the life style of the patients and their families and interfere with their lives. It's important to assess QoL of patients on haemodialysis and determine factors that alter the QoL. Aim of the work: The aim of this study was to assess QoL of patients on regular haemodialysis and determine some factors that affect the QoL. Patients and methods: This cross sectional hospital based study targeted a total coverage of patients in haemodialysis unit at Sohag University Hospital (198 patients) from September 2014 to December 2015 using KDQOL-SF ${ }^{\mathrm{TM}}$ instrument. Results: Total number of the studied patients was 198. The mean age was 48.8 years and the mean duration of dialysis was 4.19 years, most participants were males $(64.1 \%)$, married $(73.3 \%)$, illiterate $(53 \%)$, unemployed $(82.3 \%)$, and rural residents $(77.8 \%)$, their monthly income ranged from 200-500 LE (48.5\%). The most affected aspect was physical health component (PCS) which recorded the lowest scores, followed by mental component score (MCS) followed by kidney disease component summary (KDS) (95.28, 46.15, 90.04 consecutively). PCS, MCS, KDS scores were statistically significantly higher in male gender, employed, higher family income and higher level of education. Scores were insignificantly affected by marital status. Conclusion: Quality of life of patients on haemodialysis at Sohag University Hospital was impaired especially in the physical and mental component. Female gender, older age, longer duration of dialysis, low level of education, un employment and low family income leads to impaired quality of life. Much attention should be paid to improve physical and psychological aspects of the patients.
\end{abstract}

Key words: quality of life, haemodialysis.

Corresponding Author: Ahmed Fathy Hamed. Email: elnahhasahmed201022@yahoo.com

\section{Introduction}

The ultimate goal of health care is to restore or preserve functioning and well-being related to health. Health related quality of life is the functional effect of a medical condition and/or its consequent therapy upon a patient ${ }^{1}$. The purpose of health related quality of life (HRQOL) measurement is to quantify the degree to which the medical condition or its treatment impacts the individual's life in a valid and reproducible way. These measurements can then be used to measure changes in HRQOL over time, to compare the HRQOL of patients with different conditions or who receive different treatments ${ }^{2}$.

End stage renal disease (ESRD) is one of such chronic diseases causing a high level of disability in different domains of the patients' lives, leading to impaired quality of life. Survival of ESRD patients has been largely improved nowadays because of 
medical progress, advanced technology and better patient care. The availability of various renal replacement therapies (RRT) has reduced the severity of symptoms and resulted in longer survival of ESRD patients ${ }^{3}$.

End stage renal disease (ESRD) has become a worldwide public health problem ${ }^{4}$. The number of patients being treated for ESRD globally was estimated to be 2,786,000 at the end of 2011 and continues to increase at a significantly high rate. Of these 2,786,000 ESRD patients, approximately 2,164,000 were undergoing dialysis treatment [haemodialysis (HD) or peritoneal dialysis (PD)] and around 622,000 people were living with kidney transplants. At the end of year 2011, haemodialysis remained the most common treatment modality, with approximately $1,929,000$ patients undergoing haemodialysis ( $89 \%$ of all dialysis patients) and around 235,000 patients undergoing peritoneal dialysis (11\% of all dialysis patients $)^{5}$. In Egypt the Prevalence of ESRD has increased from 403 PMP (per million populations) at year 2003 to $483 \mathrm{PMP}$ at year 2004. In Sohag governorate the prevalence rate of ESRD was 276 PMP during year $2003^{6}$. Then, the prevalence rate has increased to become 316 PMP during year $2010^{7}$.

Hemodialysis therapy is timeintensive, expensive and requires fluid and dietary restrictions. Long-term dialysis therapy itself often results in a loss of freedom, dependence on caregivers, disruption of marital, family, and social life, and reduced or loss of financial income ${ }^{8}$. Hemodialysis alters the life style of the patient and family and interferes with their lives. The major areas of life affected by ESRD and its treatment includes employment, eating habits, vacation activities, sense of security, self-esteem, social relationships, and the ability to enjoy life ${ }^{9}$. Due to these reasons the physical, psychological, socioeconomic, and environmental aspects of life are negatively affected, leading to compromised quality of life ${ }^{10}$.

Accumulated data in the recent decade shows that health-related quality of life markedly influences dialysis outcomes. Evaluation of health related quality of life (HRQOL) in haemodialysis patients is becoming very important. Attention thus needs to be focused not only on how long but also on how well end stage renal disease (ESRD) patients' live ${ }^{11}$. Assessment of Health related quality of life in haemodialysis patients helps to plan the individual strategy of treatment, to determine the efficacy of medical intervention and to evaluate the quality of medical care. It provides the opportunity to evaluate the psychological burden of chronic disease, and the effect of specific treatment ${ }^{12}$. It also helps in comparing alternative treatments, improving clinical outcomes, facilitating rehabilitation of ESRD patients, and enhancing patient satisfaction. Several authors have suggested that regular HRQoL monitoring become part of regular ESRD patient assessment and incorporated into the continuous quality assurance and quality improvement systems ${ }^{13}$.

Aim of the work: This study aimed to assess quality of life of the haemodialysis patients in Sohag University Hospital through assessing different domains of quality of life of the patients as physical, mental, social domains.

\section{Patients and Methods:}

A cross sectional hospital based study, targeted at total coverage of patients on chronic haemodialysis at Sohag University Hospital . 
The period of study was from September, 2014 to December, 2015. Eligibility criteria: All adult patients of any age, whether males or females who were on regular haemodialysis at the haemodialysis Unit of Sohag University Hospital at time of study were asked to participate. The patient who accepted to participate in the study and gave a written consent (which is included in the questionnaire) were interviewed. Accordingly the total number of patients on regular haemodialysis during period of study were 215 patients. Of them 198 were enrolled in the study and the rest refused to participate. The respondent rate was $92 \%$.

Study tool: An interview was conducted using a questionnaire. It included 2 parts; the first part included basic socio demographic data. The second part is the kidney disease quality of life short form questionnaire (KDQOL-SF ${ }^{\mathrm{TM}}$ ) which comprised questions that cover quality of life (QOL) domains ${ }^{14}$. Demographic data and economic data included data about gender, age , residence, marital status, educational level, occupation, duration of dialysis, monthly family income and income satisfaction.

The KDQOL-SF ${ }^{\mathrm{TM}}$ is a multi-item measure developed for individuals with kidney disease and on dialysis. It consists of data about physical, mental health state of the patient and his (her) kidney disease: (a) Physical health components summary (PCS) included the following items: Physical functioning (10 items), role-physical (4 item), bodily pain (2 item) and general health (5 items). (b) Mental health component summary (MCS) included the following: Fatigue/energy (4 items), social functioning (2 items), role-emotional functioning (3 items) and emotional wellbeing (5 items). (c) Kidney disease component summaries
(KDS) included the following : Symptom/problem list (12 items), effects of kidney disease on daily life (8 items), burden of kidney disease (4 items), cognitive function (3 items), work status ( 2 items), sexual function ( 2 items), quality of social interaction (3 items), sleep (4 items), social support (2 items), dialysis staff encouragement (2 items) and patient satisfaction (1 item). The final item of the questionnaire was the overall health rating item asks respondents to rate their health on a $0-10$ responses scale ranging from "worst possible (as bad or worse than being dead)" to "best possible health".

Scoring:The scoring procedure for the KDQOL-SF ${ }^{\mathrm{TM}}$ first transform the raw pre-coded numeric values of items to a 0-100 possible range, with higher transformed scores always reflecting better quality of life. Each item is put on a $0-100$ range so that the lowest and highest possible scores are set at 0-100, respectively. Scores represents the percentage of total possible scores achieved. In the second and final step in the scoring process, items in the same scale averaged together to create the scale score.

Statistical analysis: The collected data were subjected to statistical analysis using (SPSS - version 16). P-value is considered significant if less than 0.05 . $\mathrm{P}$-value is calculated using MannWhitney test.

\section{Results}

Total number of the studied patients was 198. As shown in table (1) the mean age was 48.8 years and the mean duration of dialysis was 4.19 years, most participants were males $(64.1 \%)$, married $(73.3 \%)$, illiterate (53\%), unemployed $(82.3 \%)$, and a rural residents (77.8\%), their monthly income ranged from 200-500 LE (48.5\%). 
Table (2) shows the mean score for each domain of the KDQOL-SF ${ }^{\mathrm{TM}}$ instrument among studied population. It was found that generally the most affected aspect was physical health component summary (PCS) which obtained the lowest scores, followed by mental component score (MCS) followed by kidney disease component summary (KDS) (95.28, 46.15, 90.04 consecutively).

The lowest scores were in the scales of work status, general health and energy of the patients $(20.95,25.38,32.68$ consecutively), the highest scores were the social support, quality of social interaction and cognitive function (72.94, 76.36, 86.04 consecutively).

The effect of gender, marital status, income, level of education and work status on the three component summaries was shown in table(3). PCS, MCS, KDS scores were statistically significant higher in male gender, employed, higher family income and higher level of education. Scores were insignificantly affected by marital status.

As shown in table (4) a highly significant negative weak correlation between age and the PCS, MCS, KDS ( $\mathrm{p}$-value $=0.000, \quad \mathrm{r}=0.3, \quad 0.2, \quad 0.2$ consecutively). Also highly significant negative weak correlation between duration of dialysis and the PCS, MCS, KDS (p-value $=0.000, r=0.2,0.3,0.3$ ). There was highly significant positive weak correlation family income and PCS, MCS, KDS (p-value $=0.000$, $\mathrm{r}=0.1$ ).

Also a highly significant strong positive correlation between KDS and MCS (p-value <0.001, r=0.8) as well as between KDS and PCS ( $\mathrm{p}$-value $<0.001, \mathrm{r}=0.8$ ).

\section{Discussion}

The current study gave a detailed description of QOL scores of patients on regular haemodialysis at Sohag University Hospital.

On comparing the scores of the three composites domains of the KDQOL$\mathrm{SF}^{\mathrm{TM}}$, it was found that the lowest score was seen in physical component summary $(\mathrm{PCS})$ (mean score $=30.06$ ) followed by mental component summary $(\mathrm{MCS})$ (mean score $=46.15$ ) and the highest score was the score of kidney disease component summaries (KDS) (mean score $=60.97)$. This could reflect people's ability to psychologically adapt to their situation over time. In line with the current study, the cross sectional study done in El-Minia, Egypt ${ }^{15}$ and the study done in Saudi Arabia (16) showed that PCS scores were lower than MCS and KDS scores (52.7, 54.1, 59.7 respectively). Also the study done in Egypt ${ }^{17}$, the study done in Benin, Nigeria ${ }^{(18)}$ all of them showed that PCS score was lower than MCS score and KDC score. In other words, despite the worsening of the physical health status, the mental health of dialysis patients is relatively preserved.

As regard Gender, it was found that in the current study men scored higher than women at the three main domains PCS, MCS and KDS with statistically highly significant difference.

These findings were in line with other studies in Egypt ${ }^{15,19}$ showed that men scored higher than women with statistically significant difference in the PCS and KDS scores while there is insignificant difference in the MCS score $(p$-value $=0.004,0.001,0.6)$.

This also agreed to study done in Saudi Arabia $^{16 .}$ Men scored statistically significant higher than females in the three domains PCS, MCS, KDS domains $(p$-value $=0.000,0.001,0.001$ consecutively).

However the results of the current study were different from the study done in Egypt $^{20}$ which showed no significant difference between men and 
women as regard all domains of quality of life.

As regard Marital status the current study showed that there was insignificant difference between married and unmarried patients as regard all aspects of quality of life. In line with the current study the crosssectional studies done in Saudi Arabia $^{21}$ and in Chile ${ }^{22}$ both showed insignificant difference between married and un married patients, marital status was insignificantly associated with quality of life score. However this was different from study done in Turkey ${ }^{23}$ suggested there is better perception of quality of life among people living with other persons. Living with someone more strongly influences the perceived QoL. In the current study education had a positive impact on quality of life as those who had educational level above secondary school scored higher with highly significant difference compared to those below secondary school education $(p-$ value $=0.000)$. In line with this, a study in El-Minia, Egypt ${ }^{15}$ which revealed that a higher educational level was associated with higher PCS, MCS and KDCS scores . Also the study in Alexandria, Egypt ${ }^{19}$, the study in Cairo, Egypt ${ }^{20}$ and the cross sectional study in Saudi Arabia ${ }^{24}$. As regard Employment status the current study revealed that there was significant difference between employed and unemployed in quality of life as those who had job scored higher than those who were jobless and especially in the physical aspects as it showed very high statistically significant difference ( $p$-value $=0.000$ ). While there is statistically insignificant difference between both groups as regard mental health component (MCS) while in the cross-sectional study done in china showed statistically significant difference between employed and unemployed as regards MCS scores only (pvalue $=0.05)^{25}$.

As regard family income, the current study showed that patients whose monthly family income was higher than 1000 LE scored higher and had better quality of life with highly significant difference than those whose monthly family income was lower than 1000 LE (p-value $=0.001,0.000$ ). In line with the current study, a study done in Saudi Arabia ${ }^{16}$ in which MCS and PCS scores were significantly higher among the higher income group. The results of the current study were different from the study done in china in which no statistically significant difference was found between PCS, MCS, KDS mean scores when the patients were evaluated for monthly income ${ }^{25}$.

On doing correlation coefficient analysis in the current study it has been found a highly significant strong positive correlation between the three scales of quality of life (PCS, MCS, KDS $) \quad(p$-value $=0.000, \quad r=0.8)$. This was in line with the study done in Saudia Arabia that showed moderate positive correlation between the three main scales of quality of life (PCS, MCS, KDS $)(\mathrm{P}=0.0001, \mathrm{r}=0.6)^{16}$.

On doing correlation coefficient between age and the three main domains Physical component summary (PCS), Mental component summary (MCS) and Kidney disease component summary(KDS), the current study showed highly significant negative weak correlation between age of studied haemodialysis population and PCS, MCS, KDS ( $\mathrm{r}=0.3,0.2,0.2$ respectively, $\mathrm{P}$-value $=0.000$ ).

In line with the current study the study done on 161 patients at Sheikh Khalifa Medical City in the UAE. The results showed Advanced age has been linked with the deterioration of physical activity $(r=-0.3, p=0.001$ and $r=-$ 
0.096, $\mathrm{p}=0.26 \quad$ consecutively $)^{26}$. On doing correlation coefficient analysis between duration of dialysis and the three main domains; Physical component summary (PCS), Mental component summary (MCS) and Kidney disease component summary (KDS), the current study showed highly significant negative weak correlation between duration of dialysis and PCS, MCS, KDS $(r=0.2$, $0.3,0.3$ respectively, $\mathrm{p}$-value $=0.000$ ). In the same line with the current study, the study in Egypt, which showed a negative correlation between duration of dialysis and PCS scores ${ }^{20}$ ?

Conclusion: Quality of life of patients on haemodialysis at Sohag University Hospital showed marked impairment especially in the physical and mental component. The lowest scores were in the scales of work status, general health and energy of the patients while the highest scores were

\section{References}

1. Schipper H, Clinch J, Olweny C (1996): quality of life studies: definitions and conceptual issues. Quality of life pharmacoeconomics in clinical trials, 2nd edition.

2. Osoba D, Bezjak A and Brundage M (2005): Analysis and interpretation of health related quality of life data from clinical trials. Eur J cancer 41(2): 280-287.

3. Hudson J and Johnson C (2004): Chronic kidney disease In Applied therapeutics. 8th ed. 32-31.

4. Rattanasiri S, Anothaisintawee $\mathrm{T}$, Ingsathit A, Attia $\mathrm{J}$ and Thakkinstian A(2009): Prevalence of chronic kidney disease: a systematic review and metaanalysis. Clin Neph 71(3): 244-254.

5. Jha V, Garcia G, Iseki K, Li Z, Naicker S and Plattner B (2013): Chronic kidney disease: global dimension and perspectives 382(9888): 260-72.

6. Ali Taha and Eman Abd El-Baset (2005): Epidemiology of End Stage Renal Diseased pateients on Haemodialysis in Sohag Governorate, upper Egypt. JESN 7(1): 35-46. social support, quality of social interaction and cognitive function. Female gender, older age, longer duration of dialysis, low level of education were the most important factors associated with impaired life quality. Having a job and high family income had leaded better quality of life.

Recommendations: Great interest should be specified for assessing quality of life of patients with different chronic important diseases like diabetes, hypertension, cardiac, chest or other liver diseases to know the real size of the problem and what we need to improve these patients' quality of life. The importance of health education programs in improving quality of life's score of haemodilysis patients. Rehabilitation programs will help the patients with low PCS and MCS scores.

7. Ali Taha and Ahmed Fathy Hamed (2010): Epidemiology of End Stage Renal Diseased pateients on Haemodialysis in Sohag Governorate, upper Egypt: an update.

8. Lin C, Lee B and Hicks F (2005): The phenomenology of deciding about hemodialysis among taiwanese. West $\mathbf{J}$ Nurs Res 27: 915-929.

9. Smeltzer S \& Bare B (2004): Brunner $\&$ Suddarth's textbook of medical-surgical nursing. 3rd edition.

10. Blake C, Codd M, Cassidy A and O'Meara Y (2000): physical function, employment and quality of life in endstage renal disease. J Nephrol 13(2):142149.

11. Lopes-Gresham B and Satayathum J (2003): Worldwide Dialysis Outcomes and Practice Patterns Study Committee. Health-related quality of life and associated outcomes among hemodialysis patients of different ethnicities in the United States: the Dialysis Outcomes and Practice Patterns Study (DOPPS). Am J KidneyDis 41: 605-615. 
12. Mapes D, curtin R, Schatell D and Hudson S (2005): Self-management in patients with end stage renal disease: exploring domains and dimensions. Nephrology Nursing Jornal 32(4):389-395. 13. Kalantar-Zadeh K \& Unruh M (2005): Health related quality of life in patients with chronic kidney disease. Int Urol Nephrol 37(2): 367-378.

14. Hayes D, Kallich D, Coons J, Amin N, Carter B and Kamberg C (1997): Kidney disease quality of life short form (KDQOL-SFTM) a manual for use and scoring. Published by RAND.

15. Nashwa N, Emad G, Khaled H \& Marwa G(2013): Health-related quality of life among hemodialysis patients

16.at El-Minia University Hospital, Egypt J Public Health (21):193-200.

17. Al-Jumieh A, Al-Onazi K, Binsalih S, Hejaili F and AL-sayyari A (2011): Arab Journal of Nephrology and Transplantion.

18. Amer $M$, Wahba $H$, Raafat $V$ and Refaat H (2011): Study of QOL and functional level in Egyptian elderly on chronic hemodialysis treatment. Middle East J Age Aging 8(2):3-6.

19. Elhadji F, Jacques V, Ahmed $T$ and Noriace E(2014):Quality of Life of Chronic Haemodialytic Patients at Cotonou Teaching Hospital Benin. Open Journal Nephrology, (4): 131-141.
20. Samar A, sunny A, Zahira M , Hala S and Noha A (2012): Cultural adaptation and validation of arabic version of KDQOL-SFTM in Egypt. BMC nephrology (13): 170 .

21. Heba S, Hanna $M$ and Nagwa A (2006): Health related quality of life among Egyptian patients on haemodialysis. j. med. Sci, 6(3):314-320.

22. Bayoumi M, Ali A, Abdulkareem A, Mohammed A and Jamal A (2013): Saudi J Kidney Dis Transpl 24(2): 254-259.

23. Guerra-Guerra V, Sanhueza-Alvarado O, Caceres-Espina M (2012): Rev. latinoAm. Enfermagem 20(5): 838-846.

24. Sagduyu A, Senturk V, Sezer S, Emiroglu R and Ozel S (2006):Psychiatric problems, life quality and compliance in patients treated with hemodialysis and renal transplantation. Turk Psikiyatri (17): 22-31.

25. Mandoorah Q, Faisal A, Sohaib M and Salem A (2014): Saudi J Kidney Dis Transpl.

26. Sanjeev A, Mohiuddin C and Lin y (2015):International Journal of Innovative Medicine and Health Science (4) :60-70.

27. Abdelbasit M and Kamal H (2013): Self-care Self-efficacy and Quality of Life among Patients Receiving Hemodialysis in South-East of Iran. J Family Community Med 20(2): 106-112 . 
Table (1): Socio-Demographic Characteristics of the Studied Haemodialysis Patients at Sohag University Hospital 2015.

\begin{tabular}{|c|c|c|}
\hline Variable & $\begin{array}{c}\mathrm{N} \\
\text { Total }=198\end{array}$ & Percentage (\%) \\
\hline \multicolumn{3}{|l|}{ Gender } \\
\hline Male & 127 & 64.1 \\
\hline Female & 71 & 35.9 \\
\hline \multicolumn{3}{|l|}{ Residence } \\
\hline Urban & 44 & 22.2 \\
\hline Rural & 154 & 77.8 \\
\hline \multicolumn{3}{|l|}{ Marital status } \\
\hline Single & 33 & 16.7 \\
\hline Married & 146 & 73.7 \\
\hline Widowed & 14 & 7.1 \\
\hline Divorced & 5 & 2.5 \\
\hline \multicolumn{3}{|l|}{ Family income } \\
\hline $100-200 \mathrm{LE}$ & 15 & 7.6 \\
\hline 200-500 LE & 96 & 48.5 \\
\hline $500-1000 \mathrm{LE}$ & 44 & 22.2 \\
\hline$>1000 \mathrm{LE}$ & 43 & 21.7 \\
\hline \multicolumn{3}{|l|}{ Educational level } \\
\hline$\overline{\text { Illiterate }}$ & 105 & 53 \\
\hline Read \& Write & 13 & 6.6 \\
\hline Below $2^{\text {ry }}$ school & 17 & 8.6 \\
\hline Above $2^{\text {ry }}$ school & 63 & 31.8 \\
\hline \multicolumn{3}{|l|}{ Occupation } \\
\hline No job & 163 & 82.3 \\
\hline Employee & 19 & 9.6 \\
\hline Skilled worker & 13 & 6.6 \\
\hline Student & 3 & 1.5 \\
\hline \multicolumn{3}{|l|}{ Age in years } \\
\hline Mean $\pm S D$ & $48.8 \pm 1.4$ & \\
\hline \multicolumn{3}{|l|}{ Duration of dialysis in years } \\
\hline Mean $\pm S D$ & $4.19 \pm 4$ & \\
\hline
\end{tabular}


Table (2): Mean Scores for Each Domain of The KDQOL-SF ${ }^{\mathrm{TM}}$ Instrument among Studied Population at SUH 2015.

\begin{tabular}{lrrrrr}
\hline Variable & $\begin{array}{c}\text { Mean score } \\
\text { N=198 }\end{array}$ & Median & Minimum & Maximum & IQR \\
\hline PCS & 39.06 & 38.27 & 0 & 95.28 & 37.39 \\
\hline General health & 25.38 & 25 & 0 & 90.60 & 25 \\
\hline Physical function & 43.23 & 40 & 0 & 100 & 50 \\
\hline Role-physical function & 34.87 & 50 & 0 & 100 & 50 \\
\hline Pain & 52.85 & 45 & 0 & 100 & 22.5 \\
\hline MCS & 46.15 & 52 & 0 & 100 & 43 \\
\hline Emotional wellbeing & 47.73 & 52 & 0 & 100 & 16 \\
\hline Role-emotional & 54.20 & 100 & 0 & 100 & 100 \\
\hline Social function & 49.49 & 50 & 0 & 100 & 50 \\
\hline Energy/fatigue & 32.68 & 30 & 0 & 100 & 31.25 \\
\hline KDS & 60.97 & 59.26 & 32.24 & 90.04 & 14.97 \\
\hline Symptom/problem list & 83.03 & 85.40 & 27.50 & 100 & 14.60 \\
\hline Effect of kidney disease & 75.03 & 75 & 43.70 & 100 & 16.45 \\
\hline Burden of kidney disease & 35.44 & 37.50 & 0 & 100 & 37.50 \\
\hline Cognitive function & 86.04 & 100 & 13.30 & 100 & 26.70 \\
\hline Work status & 20.95 & 0 & 0 & 100 & 50 \\
\hline Quality of social interaction & 76.36 & 80 & 20 & 100 & 33.40 \\
\hline Sleep & 65.39 & 58.30 & 26.60 & 100 & 26.70 \\
\hline Social support & 72.94 & 66.6 & 0 & 100 & 16.70 \\
\hline Dialysis staff encourgment & 55.36 & 50 & 0 & 100 & 15.62 \\
\hline Patient satisfaction & 39.94 & 40 & 0 & 80 & 40 \\
\hline
\end{tabular}

$\mathrm{IQR}=$ Interquartile range 
Table (3): The Impact of Various Patient Characteristics on Scores in the Three Composite Domains of the KDQOL-SF ${ }^{\mathrm{TM}}$ Instrument among Studied Haemodialysis Population at SUH 2015.

\begin{tabular}{|c|c|c|c|c|c|c|}
\hline & \multicolumn{2}{|c|}{ PCS } & \multicolumn{2}{|c|}{ MCS } & \multicolumn{2}{|c|}{ KDS } \\
\hline & Mean score & p-value & Mean score & p-value & Mean score & p-value \\
\hline $\begin{array}{l}\text { Gender } \\
\text { Male } \\
\text { female }\end{array}$ & $\begin{array}{l}43.92 \\
30.36\end{array}$ & $<0.001$ & $\begin{array}{l}51.20 \\
37.11 \\
\end{array}$ & $<0.001$ & $\begin{array}{l}62.70 \\
57.88 \\
\end{array}$ & 0.002 \\
\hline $\begin{array}{l}\text { Income } \\
<1000 \mathrm{LE} \\
>1000 \mathrm{LE}\end{array}$ & $\begin{array}{l}35.96 \\
50.22\end{array}$ & 0.001 & $\begin{array}{l}42.57 \\
59.07\end{array}$ & $<0.001$ & $\begin{array}{l}59.05 \\
67.92\end{array}$ & $<0.001$ \\
\hline $\begin{array}{l}\text { Work status } \\
\text { With job } \\
\text { jobless }\end{array}$ & $\begin{array}{l}47.81 \\
37.37\end{array}$ & $<0.001$ & $\begin{array}{l}55.53 \\
44.38\end{array}$ & 0.037 & $\begin{array}{l}70.14 \\
59.21\end{array}$ & 0.018 \\
\hline $\begin{array}{l}\text { Marital status } \\
\text { Married } \\
\text { unmarried }\end{array}$ & $\begin{array}{l}39.02 \\
39.16\end{array}$ & 0.908 & $\begin{array}{l}47.23 \\
43.11\end{array}$ & 0.357 & $\begin{array}{l}61.46 \\
59.61\end{array}$ & 0.315 \\
\hline
\end{tabular}

Table (4): Correlation (r) Analysis between Independent Variables (Age, Family Income, Duration Of Dialysis) and the Three Component Summaries of The KDQOLSF $^{\mathrm{TM}}$ Instrument among Studied Haemodialysis Population at SUH 2015.

\begin{tabular}{lcccccc}
\hline \multirow{2}{*}{ Variables } & \multicolumn{2}{c}{ PCS } & \multicolumn{2}{c}{ MCS } & \multicolumn{2}{c}{ KDS } \\
\cline { 2 - 7 } & $\boldsymbol{r}$ & $\boldsymbol{p}$-value & $\boldsymbol{r}$ & $\boldsymbol{p}$-value & $\boldsymbol{r}$ & $\boldsymbol{p}$-value \\
\hline Age & -0.390 & $<0.001$ & -0.251 & $<0.001$ & -0.242 & $<0.001$ \\
\hline Family income & 0.137 & $<0.001$ & 0.169 & $<0.001$ & 0.171 & $<0.001$ \\
\hline Duration of dialysis & -0.286 & $<0.001$ & -0.313 & $<0.001$ & -0.386 & $<0.001$ \\
\hline
\end{tabular}




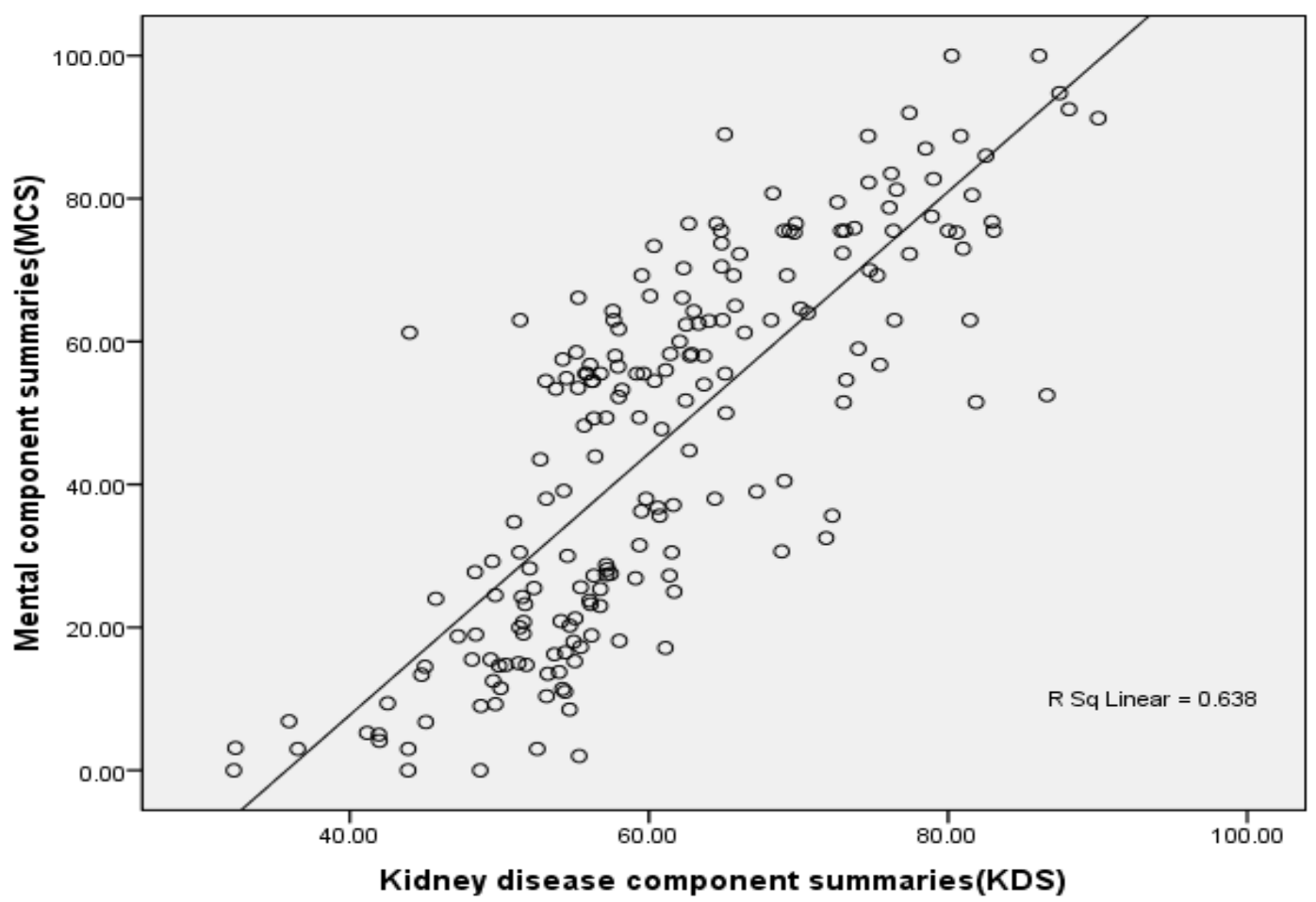

Figure (1): Scatterplot Demonstrating Positive Correlation Between Kidney Disease Summary (KDS) and Mental Component Summary (MCS) Scores of The KDQOL-SF ${ }^{\mathrm{TM}}$ Instruments Among Studied Haemodialysis Population at SUH. (r=0.80, p-value <0.001).

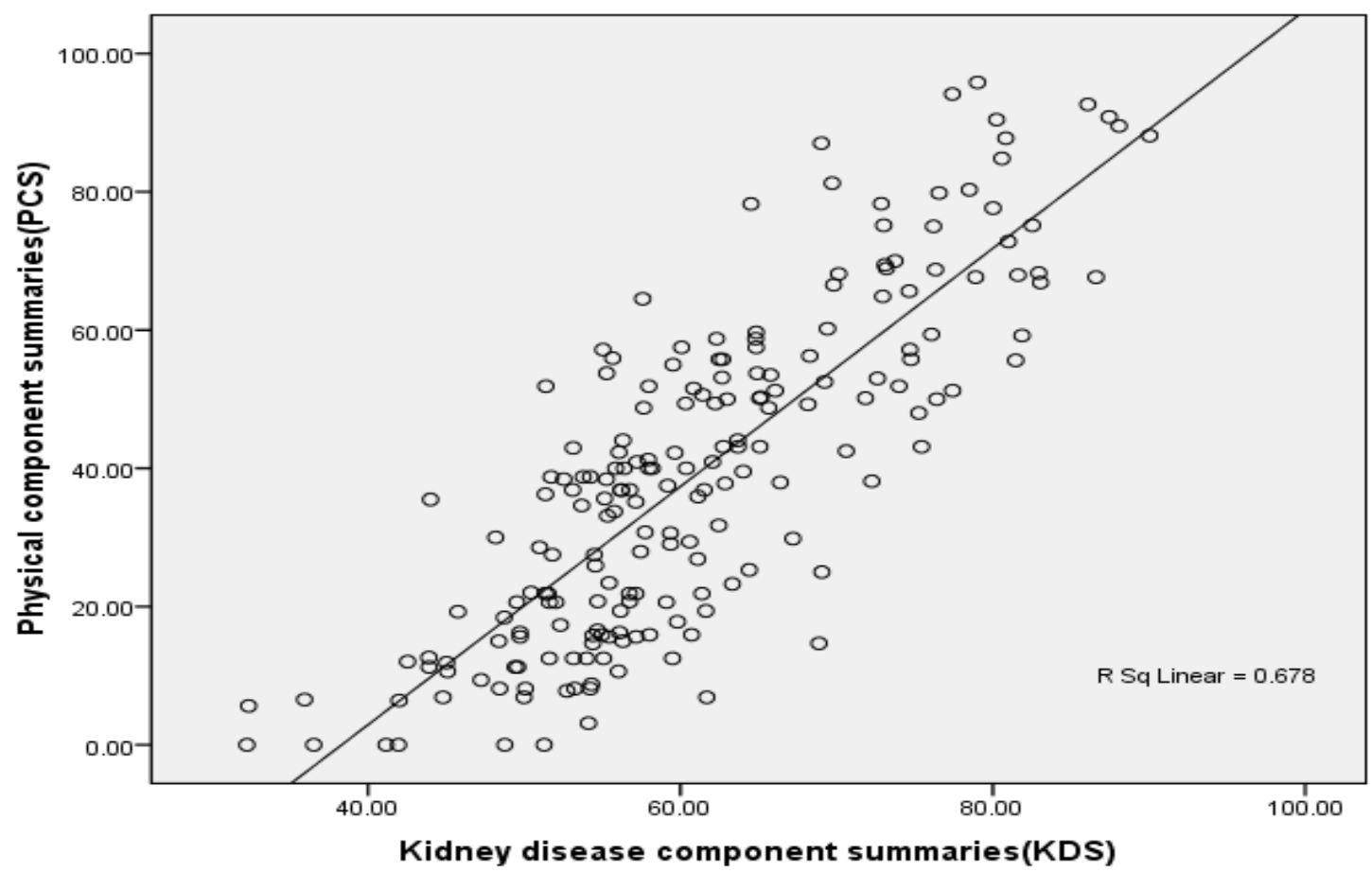

Figure (2): Scatterplot Demonstrating Positive Correlation Between Kidney Disease Summary (KDS) and Physical Component Summary (PCS) Scores of The KDQOL-SF ${ }^{\mathrm{TM}}$ Instruments among Studied Haemodialysis Population at SUH $(r=0.82$, p-value $<0.001)$. 